\title{
A Disparity of Youngsters' Fitness among Girl Students in the Public Campuses of Terai Region, Nepal
}

\author{
Suresh Jang Shahi \\ shahi.suresh123@gmail.com \\ Reader \\ Central Department of Education, T.U., Kirtipur
}

\begin{abstract}
The objective of this paper presents to compare the disparity of youngsters'fitness among girl students between Saptagandaki and Nav Kshitiz public campuses of Terai region, Nepal. It hypothesized that there is significance difference between them. Among test items of AAHPER standing broad jump, shuttle run and sit-ups (flexed leg) have applied as tool of this paper. Altogether 40 youngsters'girls were the respondents, whereas 20 students from each campus designated through multistage sampling method. While comparison to the mean scores of Nav Kshitiz youngsters, the Saptagandaki youngsters found better fitness in all three test scores as well as composite score. Furthermore it applied p-value of t-test, there were found significance difference in the youngsters'fitness scores an overall test items between both groups. Hence, hypothesis is accepted. In comparison to the Nav Kshitiz youngsters, the Saptagandaki youngsters have more involved in the physical works and sporting activities.
\end{abstract}

Keywords: Fitness, physical fitness, standing broad jump, shuttle run, sit-ups (flexed leg)

\section{Introduction}

Fitness is a condition that helps us for better look, feel and do our best. The ability to perform daily tasks vigorously and alertly, with energy left over for enjoying leisure-time activities and meeting emergency demands (Sing, Bains, Gill, \& Brar, 2012). Fitness is important to physical performance and good health. Physical fitness and motor fitness are the types of fitness test (Davis, Bull, Roscoe, \& Roscoe, 2000).

Fitness test has been commonly using as an assessment of young peoples' fitness both in schools and in public health. The components of health-related fitness are cardiovascular, body composition, flexibility and muscular endurance which have tested because of their relation to health/disease outcomes in later life. It has argued that among other factors, a young person's fitness may determine how much physical activity they actually participate in. In a pediatric population Cale and Harris point out that circumstances such as biological, maturity, hereditary amongst others contribute to fitness level (Cale \& Haris, 2009 as cited by Shahi, 2017, p. 89). 
Physical fitness tests aim to look at anatomical and physiological components that determine a person's physical performance capacity. The individuals' fitness can measure the components of physical fitness, which are strength, endurance, speed, flexibility and body composition (Davis, Bull, Roscoe, \& Roscoe, 2000). Physical fitness is some general athletic terms, means the capability of the individual to meet the varied physical demand made by a sporting activity as well as regular exercise, without reducing the person to an excessively fatigued state(Davis, Bull, Roscoe, \& Roscoe, 2000 as cited by Shahi, 2018, p. 609).Physical fitness someone has defined as the absence of disease of individual and someone state of being muscular development, as well as the ability to perform sport skills. Measuring the body's strength, endurance and flexibility is the most inclusive definition (Uppal, Gautam, Manjul, Sing, Sharma, Kapoor, Baweja \& Dar, 2005).Physical fitness denotes the performance of heart and lungs, and muscles, as well as daily activities without fatigue. Individual can develop their basic physical fitness through improvement of endurance, strength, flexibility, speed, agility etc. (Johnson \& Nelson, 1988). Fitness is influenced by age, sex, heredity, personal habits, exercise and eating habits, diet, attitude, towards life, anxiety, tension, and stress, values of physical fitness, institutional curricular, and states' policy/legislation (Shahi, 2016).

The strength, power, speed, Agility, balance, flexibility, local muscle endurance, cardiovascular endurance, strength endurance, and co-ordination are components of physical fitness. However,the four elements e.g. endurance, strength, speed and flexibility, as well asbody composition also considered. (Sing, Bains, Gill, \& Brar, 2012). The pull-ups for boys, flexed arm hang for girls, sit-ups, shuttle run, standing broad jump, 50- yard dash and 600-yard runwalk has developed from AAHPER. These batteries of fitness tests have applied to measure the individuals' fitness (Mathews, 1978).The eleven components of physical fitness are agility, balance, body composition, cardiovascular endurance, coordination, flexibility, muscular endurance, muscular strength, power, reaction, time and speed (Shahi, 2015).

Standing broad jump test administered to measure the explosive legs power. Explosive legs power is an ability to exert maximum muscular contraction in an explosive pace of movements of legs. It generates through strength and speed i.e. Power $=$ Work/Time (Jha, 2010). Shuttle run test has applied to measure the agility of an individual. The agility is the ability to perform a series of explosive power movement in rapid succession in opposing direction(Sing, Bains, Gill, \& Brar, 2012 as cited by Shahi 2020, p. 2). Sit-ups/flexed leg test has applied to measure the abdominal power of an individual. The abdominal power is the ability to release maximum force of abdominal muscles in a fastest possible time(Davis, Bull, Roscoe, \& Roscoe, 2000 as cited by Shahi 2015, p. 2).

Physical fitness study in different areas showed that Sharma (2015)has conducted a study of physical fitness between girl students of institutional and community schools in Dhanusha district. He found insignificant difference in standing broad jump and sit-ups test scores however significant difference in shuttle run test. Gurung (2015) has also conducted a similar study of physical fitness between indigenous and non-indigenous youth boys in Gorkha district. He found insignificant difference in shuttle run and sit-ups test scores however significant difference in standing broad jump test.Furthermore, Bohara (2009) has conducted a study on physical fitness 
between Tharu and Madheshi boy students in Bardiya district. In comparison to the mean scores of Madheshi boys, the Tharu boys were better in fitness performance. Moreover, he has found significant different in standing broad jump, shuttle run and sit-ups/flexed legs test between them. Bist has conducted a research on physical fitness between khokho and basketball national players of Nepal. Among six test items of AAHPER, insignificant difference found between these groups except sit-ups test (Bist, 2019). Furthermore, Rai has studied on comparison of physical fitness between basketball players and karate players of APF club. Except standing broad jump among seven test items of AAHPER youth fitness test, significant difference were found between both groups (Rai, 2017). Sharma has conducted a comparative study on physical fitness between Tharu and Chhetri boy students in Dang district. He concluded that significant difference found in majority of test items, however no significant difference found in pull-ups and knee bent situps (Sharma, 2017). Likewise, KC conducted a comparative study on physical fitness between Raji and Badistudents in Surkhet district, found no significant difference in majority of these test items between them (KC, 2016).

It concluded that from above reviews and literatures, fitness is a competency to perform efficiently, to enjoy leisure time, to be healthy life, to resist disease, and to cope with emergency situations. Fitness can measure the physiological parameters such as heart rate, oxygen uptake and flexibility. Furthermore, we are concluded that fitness can be determined through strength, speed; agility etc.

Saptagandaki, campus is one of the research areas, situated in Bharatpur city of Chitwan district. The Chitwan district is one of seventy-seven districts of Nepal, and is located in southwestern part of province 3. The Chitwan district headquarters isBharatpur, fifth largest city of Nepal. The Bharatpur is only one metropolitan city of this district. This city lies in Chitwan valley, one of Inner Terai valleys of Nepal. The Bharatpur city situated in the plain area and called Terai belt,almost total population has covered by pahadian ethnicities. In Saptagandaki campus, respondent girls dominated by Tharu and Chhetri ethnicities however Brahmin, Newar, Gurung and Magar were the nominal respondents. The further research campus is Nav Kshitiz, which is located in Bardibas city of Mahottari district. Mahottari, a part of state number 2, is one of the seventy-seven districts of Nepal. Bardibas is newly established urban area which lies to the northern part of Mahottari district. However, it has diversity in habitation both Pahadian and Madheshi ethnicity. This district has the higher density of Madheshi or as Maithilicommunity. In Madheshi culture, parents arenarrow-minded and having captivity lifefor girls. Furthermore, the respondent girls of Nav Kshitiz campus designated from Madheshi backgrounds e.g. Shah, Gupta, Jha, Yadav and Muslim etc.

The Nav Kshitiz campus of Bardibas is a newer affiliated campus than Saptagandaki campus of Bharatpur, both are public campuses of Nepal. In comparatively, the Saptagandaki campus have better in sports' facilities, physical teacher and physical infrastructure, as well as financially, then the Nav Kshitiz campus. Therefore, the student of Nav Kshitiz cannot get opportunities of games and sports than Saptagandaki campus. The Chhetri cast is famous in armed force as well as sports in Nepal. Next cast, Tharu is an ethnic people of Nepal. They are physically strong and popular in sports in Nepal (Shahi, 2018). Furthermore he explained that the Pahadian 
communities, family members are being socio-culturally open minded in sporting activities. They have got an opportunity to take part in sporting activities even in their leisure time. Conversely, Madheshi girls did not have these opportunities. Shahi (2015) described his research report the girls in Madheshicultures have least opportunity to participate in physical and sporting activity. In comparison to the girls of Pahadian ethnicities, the girls of Madheshi ethnicities get less opportunity to participate in sporting activity due to traditional and fanatical societies. This kind of research paper in similar topographical area but different ethnicities hasn't submitted so far. Therefore, the objective and hypothesis of this research paper formulated based on these above issues and research gap. So, the paper entitled "A Disparity of Youngsters' Fitness among Girl Students in the Public Campuses of Terai Region, Nepal.

\section{Objective}

The objective of this paper was to compare the disparity of youngsters' fitness among girl students between Saptagandaki and Nav Kshitizpublic campuses of Terai Region, Nepal.

\section{Hypothesis}

$H_{1}$ : There is significance difference in youngsters' fitness among girl students between the Saptagandaki and Nav Kshitiz campuses.

\section{Methods and Tools}

Methods: This research paper has based on quantitative data as well as descriptive or as comparative design (Best \& Khan, 2002). The data used in this paper collected from the primary source, taken from the field. The test items of AAHPER Youth Fitness Tests measured in youngsters' performance. The data compared between youngsters' girl students of health and physical education (HPE) which taken from Saptagandaki campus of Chitwan district and Nav Kshitiz Campus of Mahottari district. Topographically, these research areas were in Terai region. There applied multistage sampling method in selecting the respondents. The bachelor first year girl students of TU who participated in practical examination of physical education subject were the respondents of this paper. These practical examinees respondents designated from Saptagandaki campus and Nav Kshitiz campus. Thus the respondents' campuses were in the convenient sampling method. Likewise, there were 20 Pahadian ethnicities from Saptagandaki campus and 20 Madheshi ethnicities from Nab Kshitiz campus both respondents designated by census method. Hence, altogether 40 youngsters' girl students were the respondents for this paper.

Tools: The AAHPER Youth Fitness Test launched a Youth Fitness project in 1957, it has known as American Association for Health, Physical Education and Recreation (Mathews, 1978). This AAHPER Youth Fitness Test applied for the tool of this paper. There were applied only three items e.g. standing board jump, shuttle run and sit-ups (flexed-leg) from AAHPER (Mathews, 1978). These standing board jump, shuttle run and sit-ups (flexed-leg) test items used to measure the agility and speed, explosive power of legs and strength of abdominal muscle, as well as balance of youngsters' fitness respectively. The raw scores of youngsters' fitness collected through these test items. 


\section{Results and Discussion}

The standing board jump, shuttle run, and sit-ups (flexed leg)administrated for youngsters' fitness among youngsters' girl students. The fitness data of youngsters obtained from these test items. These raw data were converted incases and statistics e.g. mean, standard deviation, standard error, maximum, minimum, range, coefficient of variation, $p$-value of t-test (at $\alpha=0.05$ ) and conclusion. These cases and statistics used to compare the fitness ability among youngsters' girl students between two campuses of Terai region. Moreover, the sep values of t-tests and its' conclusions were used to compare the results and discussions, as well as to verify the hypothesis of this paper. There were found statistically significant between groups among the youngsters' girl students. The cases and statistics of these fitness tests results were carried out Saptagandaki and Nav Kshitiz campuses, these results and discussion, as well as analyzed are given in following components:

Standing Broad Jump: Standing broad jump is one of the major fitness tests of physical fitness. The purpose of this test is to measure the explosive leg power of an individual and youngsters' girls. The cases and statistics of test on standing broad jump results and discussion are givenin Table 1.

Table 1: Cases and Statistics of standing broad jump between youngsters'groups

\begin{tabular}{lcc}
\hline Cases & Saptagandaki Students & Nav Kshitiz Students \\
\hline Mean & 1.64 & 1.42 \\
Standard Deviation & 0.14 & 0.10 \\
Standard Error & 0.03 & 0.02 \\
Minimum & 1.35 & 1.26 \\
Maximum & 1.90 & 1.65 \\
Range & 0.55 & 0.39 \\
CV (\%) & 8.80 & 7.25
\end{tabular}

p-value oft-test (at $\alpha=0.05), p=0.000$

Conclusion This test result is significant at 0.05 level of significance $(p<\alpha)$

Table 1 shows that the $p$-value $=0.000$ is significance at 0.05 level of significance $(p=0.000<\alpha=$ 0.05 ) from the above table, it is enough evidence there is difference between the mean score of Saptagandaki and Nav Kshitizyoungsters. Statistically, it concluded that there was significant difference between the mean score of Saptagandaki and Nav Kshitiz youngsters' groups. This result has supported to accept the alternative hypothesis of this paper. In comparison to the youngsters of Nab Kshitiz youngsters, the Saptagandaki youngsters' more involved in sporting activities and physical work.

Shuttle Run: Shuttle-run is also a key component of physical fitness. The purpose of this test is the capacity to change course, controlling the direction and position in fast motion of our body while maintaining our momentum. Furthermore, measuring the agility and speed are the main purpose of this test. The results and discussion of this cases and statistics of this test are given in Table 2. 
Table 2: Cases and Statistics of shuttle run between youngsters' groups

\begin{tabular}{lcc}
\hline Cases & Saptagandaki Students & Nav Kshitiz Students \\
\hline Mean & 11.84 & 12.60 \\
Standard Deviation & 0.73 & 1.05 \\
Standard Error & 0.16 & 0.24 \\
Minimum & 10.90 & 11.30 \\
Maximum & 13.51 & 16.12 \\
Range & 2.61 & 4.82 \\
CV (\%) & 6.17 & 8.35
\end{tabular}

p-value oft-test (at $\alpha=0.05$ ), $p=0.006$

Conclusion This test result is significant at 0.05 level of significance $(p<\alpha)$

The above Table 2,the mean score the Saptagandaki youngsters is 11.84 seconds and the mean score of Nav Kshitiz youngsters' is 12.60 second son shuttle run test. Due to the duration of time of mean scores, the Saptagandaki youngsters' have finished shorter time than Nav Kshitiz youngsters. This means Saptagandaki youngsters were faster and agile in speed than Nav Kshitzyoungsters. Likewise, statistics scores of standard deviation, maximum, minimum range and coefficient of variation of Saptagandaki youngsters' girls are lesser than Nav Kshitiz. Furthermore, $p$-value of t-test score of two campuses is 0.006 which is less than $0.05(p<\alpha)$ at 95 percent confidence interval. Hence, it is evidence in the data to accept the alternative hypothesis. Therefore, there is significant difference in shuttle run scores between the youngsters' girls of these two campuses. Considering that Saptagandaki youngsters were more involved in jogging, walking, cycling, and yogic activities, as well as more family support to involve in sports.

3.3 Sit-Ups (Flexed Leg): Sit-ups is a next fitness test of physical fitness. The purpose of this test is to measure the abdominal strength of an individual and youngsters' girls. The cases and statistics of this test results as well as discussion are given in following Table 3:

Table 3: Statistics scores of sit-ups (flexed leg) among youngsters'groups

\begin{tabular}{lcc}
\hline Cases & Saptagandaki Students & Nav Kshitiz Students \\
\hline Mean & 9.30 & 5.40 \\
Standard Deviation & 8.75 & 2.64 \\
Standard Error & 1.96 & 0.59 \\
Minimum & 1.00 & 1.00 \\
Maximum & 30.00 & 13.00 \\
Range & 29.00 & 12.00 \\
CV (\%) & 94.13 & 48.96 \\
\hline
\end{tabular}

p-value oft-test (at $\alpha=0.05$ ), $p=0.032$

Conclusion This test result is significant at 0.05 level of significance $(p<\alpha)$ 
Table 3 shows that the mean score of Saptagandaki youngsters in sit-ups (9.30) is greater than Nav Kshitz youngsters (5.40). Likewise, standard deviation, maximum, minimum, range, and coefficient of variation scores of Nav Kshitzyoungstersare less than Saptagandaki youngsters. This means, Saptagandaki youngsters have better abdominal strength. The greater score of standard deviation indicate that the individual score more dispersed from mean and also the higher value of coefficient of variation indicates that there is wider dispersion in each individual score. If the value of range, standard deviation and coefficient of variation are lesser score, this means lower score is better than higher score (Shahi, 2018). Hence the group of Saptagandaki youngsters was better in sit-upsthan Nav Kshitzyoungsters. Moreover, p-value of two groups is 0.032 , which is less than $0.05(p<\alpha)$ confidence interval. Therefore, further evidence found to accept assumed hypothesis. Hence, significant difference has found between sit-upsamong youngsters' girls. Due to the fieldwork, jogging, walking, cycling, and sporting activities as well as regular physical activities; Saptagandaki youngsters have got better abdominal power.

Composite Score: The composite score is average of these test items which was carry out from each group of youngsters. The result and discussion of composite score cases as well as statistics is specified in Table 4.

Table 4: Standard scores of composite scores between girl students'groups

\begin{tabular}{lcc}
\hline Cases & Saptagandaki Students & Nav Kshitiz Students \\
\hline Mean & 198.37 & 147.44 \\
Standard Deviation & 21.81 & 18.04 \\
Standard Error & 4.88 & 4.03 \\
Minimum & 160.05 & 94.48 \\
Maximum & 235.16 & 177.83 \\
Range & 75.11 & 83.35 \\
CV (\%) & 11.00 & 12.24 \\
\end{tabular}

p-value oft-test (at $\alpha=0.05), p=0.000$

Conclusion This test result is significant at 0.05 level of significance $(p<\alpha)$

The above table shows that the mean score of Saptagandaki students is 198.36 and the mean score of Nav Kshitiz students is 147.43 in composite score. The mean score of Saptagandaki students is better than Nav Kshitiz students. Furthermore there were applied t-test of p-value to see the significant difference between the means of Saptagandaki and Nav Kshitiz students. Moreover, $p$-value of t-test scores $=0.000$ is significance at 0.05 level of significance. Furthermore, $p$-value of both groups is 0.000 which is less than $0.05(p<\alpha)$ confidence interval. Hence, t-test of p-value of significance difference between means shows that there is significance difference in composite scores between both groups of youngsters. This result assists it is sufficient evidence in the 
data to accept the hypothesis. This difference is due to the Saptagandaki youngsters were more involved in jogging, walking, cycling, sports and yoga, as well as regular physical activities.

Hypothesis Testing: In order to comparison of fitness test of hypothesis previously formulated as “There Is Significance Difference in Youngsters' Fitness among Girl Students between the Saptagandaki and Nav Kshitiz Campuses". These above tables and results, as well as discussion, there are enough evidence to accept this assumed hypothesis. In comparison to the fitness performance of Nav Kshitiz youngsters, the Saptagandaki youngsters had more involved in sporting and fitness activity. So the fitness performance has seen difference between both counterparts.

\section{Conclusions}

The Saptagandaki youngsters has found better fitness than Nav Kshitiz youngsters in statistical mean scores of standing broad jump, shuttle run and sit-ups, as well as composite score. The $t$-test of $p$-value score of both campuses, $p$ - values were less than $\alpha$ in standing broad jump $(p=0.000$ $<\alpha=0.05)$, shuttle run $(p=0.006<\alpha=0.05)$, sit-ups $(p=0.032<\alpha=0.05)$ and composite $\operatorname{score}(p$ $=0.000<\alpha=0.05$ ) at 0.05 level of significance. Hence, there was found significance difference between means of youngsters' fitness among girls. Hence the hypothesis of this paper is accepted. The difference is due to the involvement of Saptagandaki youngsters' more in physical work, fitness and sporting activities than Nav Kshitiz' youngsters. The community, family, social institution, television, radio, booklets, magazines, internet and sports environment as well as physical teacher were the main source of fitness knowledge. These factors have favored this significance difference of result. For the promoting of the existing fitness of youngsters', fitness and physical training related seminar, workshop and research activities should conducted in all educational institutions of Nepal. This research suggests that the leisure time of people for per day should spend in physical and sporting activities. The government should be managed the physical education teacher in each and everywhere school and campus of Nepal.

\section{References}

Best, J. W. \& Khan, J. V. (2002). Research in education. New Delhi: Prentice-Hall of India.

Bist, K. (2019). Physical fitness among the national player of khokho and basketball teams of Nepal. T.U., Kirtipur: An Unpublished Master Degree Thesis Submitted to Physical Education Department, University Campus.

Bohara, K. (2007). Comparison of physical fitness between Tharu and Madheshi students of Bardiya district. T.U., Kirtipur: An Unpublished Master Degree Thesis Submitted to HPPE Department, University Campus.

Davis, D., Bull, R., Roscoe, J. \& Roscoe, D. (2000).Physical education and the study of sports. London: Harcourt Publisher. 
Gurung, G. (2006). A comparative study on physical fitness of indigenous and non-indigenous youths. T.U., Kirtipur: An Unpublished Master Degree Thesis Submitted to HPPE Department, University Campus.

Jha, A. K. ((2010). Test, measurement and evaluation in physical education. Siraha, Nepal: Renu Prakasan.

Johnson, B. L. \& Nelson, J. K. (1988).Practical measurements for evaluation in physical education. New Delhi: Surjeet Publications.

KC, B. B. (2016).Comparative study on physical fitness between Raji and Badi students in Surkhet district..T.U., Kirtipur: An Unpublished Master Degree Thesis Submitted to Physical Education Department, University Campus.

Mathews, D. K. (1978).Measurement in physical education.Philadelphia, London, Toronto: W.B. Saunders Company.

Rai, R. K. (2017). Comparison of physical fitness between basketball and karate players of APF club. T.U., Kirtipur: An Unpublished Master Degree Thesis Submitted to HPPE Department, University Campus.

Shahi, S. J. (2015). Comparison of general physical fitness between the girl students of Saptagandaki and Nava Kshitiz campus. Unpublished Mini-Research Report, University Grant Commission.

Shahi, S. J. (2016). Physical fitness among the boy students of public campuses: A comparative analysis. Perspectives on Higher Education, Journal of TUTA, Vol. 9, pp. 141-149.

Shahi, S. J. (2017). A contrast of youngsters' fitness in the hilly and terai area of Chitwan district of Nepal.International Journal of Yoga, Physiotherapy and Physical Education, Vol. 2 (3), pp. 89-92.

Shahi, S. J. (2018). Attitude of physical fitness among girl students in Nepal: International Journal of Scientific and Research Publication (IJSRP), Vol. 8 (9), pp. 609-613, DOI: 10.29322/IJSRP.8.9.2018.p8182.

Shahi, S. J. (2018). Attitude of yoga among girl students in public campuses of Nepal: Scientific Research Journal (SCIRJ), Vol. VI (VIII), pp. 54-59.DOI: 10.31364/SCIRJ/v6.i8.2018. $\mathrm{P} 0818550$.

Shahi, S. J. (2020). ). Physical fitness between the girl students of Sarlahi campus and Gaurishankaryadav Rautahat campus. TU, Kirtipur: An Unpublished Mini-Research Report. Research Directorate, Rector's Office.

Sharma, G. (2015). Physical fitness of institutional and community secondary level girl students in Mithila municipality of Dhanusha district. T.U., Kirtipur: An Unpublished Master Degree Thesis Submitted to Physical HPPE Department, University Campus. 
Sharma, Y. N. (2017). Physical fitness between Tharu and Chhetri boys of secondary level in Dang district.T.U., Kirtipur: An Unpublished Master Degree Thesis Submitted to Physical Education Department, University Campus.

Singh, A., Bains J. Gill S. \& Brar S. (2012).Essentials of physical education. Ludhiana: Kalyani Publishers.

Uppal, A. K., Gautam, G. P., Manjul, J. S., Sing, M. K., Sharma, S. N., Kapoor, I. P., Baweja V. K., \& Dar, M.(2005). Physical education and health. Delhi: M/s Friends Publication. 